\title{
Local Shear Stress-Strain Response of Sn-3.5Ag/Cu Solder Joint With High Fraction Of Intermetallic Compounds: Experimental Analysis
}

\author{
Soud Farhan Choudhury * Leila Ladani \\ Department of Mechanical Engineering \\ University of Connecticut, Storrs, CT 06269-3139 \\ *soud.choudhury@uconn.edu; Tel: 860-617-8623 \\ lladani@engr.uconn.edu, Tel. 860-486-8994
}

\begin{abstract}
Current trend in miniaturization of microelectronic devices is the motivating factor for size reduction of joints and interconnects. The electronic industry is expecting to reduce the scale of interconnects in the next generations microelectronic devices. Mechanical behavior of these joints will significantly be different from traditional solder joints due to the effects such as geometrical and microstructural constraints, anisotropy caused by the reduction in a number of grains, and the presence of brittle intermetallics (IMCs). Mechanical experiments at this scale are very challenging. This study was focused on investigating the effect of different volume fraction of

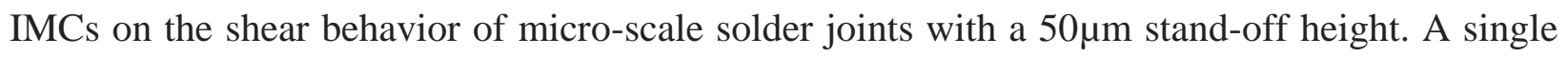
lap-shear specimen was designed to conduct the study. Two Copper $(\mathrm{Cu})$ substrates were soldered together with $\mathrm{Sn}-3.5 \mathrm{Ag}$ solder foil and a thickness of $50 \mu \mathrm{m}$ was achieved. The soldering temperature of $260^{\circ} \mathrm{C}$ and soldering time of 10,30 and 60 minutes were utilized to achieve approximately $40 \%, 60 \%$ and $80 \%$ IMCs of total joint thickness. The experiments were conducted using a micro-tensile tester which is integrated with an optical microscope for monitoring and observing deformation in the testing materials. To investigate the local shear strain behavior, an optical technique along with a developed image processing computer program was used. The single lap-shear tests were conducted with the shear strain rate of $0.015 \mathrm{~s}^{-1}$ and $0.15 \mathrm{~s}^{-1}$ to observe
\end{abstract}


its effect on shear stress-strain behavior. The study shows that the ultimate shear strength and strain to failure are largely dependent on the volume fraction of IMCs. On the other hand, the far-field or nominal shear strain is totally different than the local shear strain behavior at solder joint region. Fractography analysis was conducted to investigate the possible failure mechanism. A ductile to brittle fracture mode transition along with dominant interfacial delamination is witnessed when the solder joints had a higher volume fraction of IMCs than bulk solder. Effect of different shear strain rates on the shear strength, failure strain and fracture mode were also investigated. Different shear strain rates tend to have an insignificant effect on the shear strength of the joint whereas the failure strain decreases considerably at higher shear strain rate.

Key words: Solder joint, IMC, lap-shear, optical measurement of local displacements, shear stress, shear strain, failure modes

\section{INTRODUCTION}

Miniaturized solder joint in microelectronics with a standoff height of $20-60 \mu \mathrm{m}$ contains a large volume fraction of intermetallics (IMCs). Due to its completely different mechanical properties than bulk solder, IMC materials play a major role in the mechanical strength and reliability of the solder joint. IMCs such as $\mathrm{Cu}_{6} \mathrm{Sn}_{5}$ and $\mathrm{Cu}_{3} \mathrm{Sn}$ form in between solder/Cu interface due to the diffusion of copper $(\mathrm{Cu})$ into bulk solder $(\mathrm{Sn})$. In Cu pillar micro bumps, major portion of bulk $\mathrm{Sn}$ converts into IMCs during the diffusion process, and therefore, the Cu pillar bump is typically left with small volume fraction of ductile solder alloy [1,2]. These IMCs are necessary for good metallurgical bonding. However, their excess volume and growth may induce a significant effect on the reliability. 
IMC growth behavior at reflow process is largely controlled by the rate of cooling [3-5]. Zhang et al. [5] have identified liquid state reacting time among with the cooling rate to be the most influencing factors in IMC growth behavior in $\mathrm{Sn}-\mathrm{Ag} / \mathrm{Cu}$ solder joint. Slow cooling rate using furnace provides higher interfacial IMC thickness whereas faster cooling rate by water quenching provides smallest interfacial IMC thickness [5].

During the lifetime of microelectronics, solder joints present in the electronic package are often subjected to mechanical loading. Higher volume fraction of IMCs results in a more dominant mechanical role which is not very well known. It has been shown that interfacial IMCs tend to have a major role in determining the reliability of solder joints due to their different mechanical properties [6-9]. Recently, IMC thickness effect on shear behavior of the solder joints has been explored in some studies [10-16]. Variation in IMC thickness were achieved by either varying the reflow temperature [11,12], or using isothermal aging [13-15]. Goh et al. [11] has investigated the effect of reflow temperature on the shear strength of the $\mathrm{Sn}-\mathrm{Bi} / \mathrm{Cu}$ solder joints. They observed an increase in ultimate shear strength with the increased reflow temperature $\left(200^{\circ} \mathrm{C}\right.$ to $\left.260^{\circ} \mathrm{C}\right)$ while no effect on the elastic regime. Due to the higher elastic energy release observed at higher reflow temperature samples, the crack propagation resistance was higher which gave higher ultimate shear strength.. Bhat et al. [12] found an increase in shear strength of SAC387/Cu joint with the increase in reflow temperature which was attributed to the increase in thickness of $\mathrm{Cu}_{6} \mathrm{Sn}_{5}$ and $\mathrm{Ag}_{3} \mathrm{Sn}$ IMC phases at higher reflow temperatures.

Xiaowu Hu et al. [14] observed that with the increase in aging time, shear strength of $\mathrm{Sn} 37 \mathrm{~Pb} / \mathrm{Cu}$ solder decreased. The reason was explained to be either the increase in brittle IMC layer thickness or the grain coarsening of Sn-rich phase in solder. Zhu et al. [17] investigated the effect of aging on the interfacial microstructure and reliability of $\mathrm{SnAgCu}$ solder. They found with the aging at 
higher temperature $\left(180^{\circ} \mathrm{C}\right)$, failure mode transmitted from ductile to brittle due to excessive IMC thickness. They did not take the solder grain coarsening into account.

However, all these experimental studies were conducted on solder joints where the volume fraction of IMCs were insignificant compared to the volume fraction of bulk solder. Shear behavior and failure mechanism may change drastically if a solder joint contains more IMCs than bulk solder.

Previous practices on increasing IMCs thickness using aging may be questionable due to the fact that grain coarsening may occur as IMCs grow. Additional factors such as Kirkendall voiding could also deviate the results from the actual practice. To study, IMC thickness effect alone, we must decouple the two phenomena. Keeping a constant cooling rate with an increase in the soldering time may increase the IMC thickness without altering the bulk solder microstructural characteristics extensively. This study was designed and aimed to investigate the effect of the presence of IMCs at different amount on the shear stress-strain response and failure of micro-scale solder joints with $50 \mu \mathrm{m}$ thickness using a single lap-shear test.

\section{EXPERIMENTS}

\subsection{Experimental Parameters Selection}

Reducing the variables that could affect the shear response was an important step during the experimental design. In general; variation in gap size [18], reflow profile [16] and cooling rate $[4,5]$ tends to effect the shear response of the solder joint due to the changes in solder microstructure, morphologies and IMC growth. The experiments were designed in such a way that the IMC thickness variation would be the only variable that would control the shear response. For this reason, soldering temperature was kept constant to $260^{\circ} \mathrm{C}$ while soldering time was varied to achieve different rate of $\mathrm{Cu}$ dissolution and thus IMC thickness. Similar furnace cooling rate of 
$\sim 2^{\circ} \mathrm{C} / \mathrm{min}$ was used for all samples to minimize the variation in solder microstructure from sample to sample. The test, specimen design and fabrication process were implemented meticulously to minimize the solder joint thickness variations.

\subsection{Experimental Procedures}

\subsubsection{Specimen Design and Fabrication}

The dimensions of the single lap shear specimen are provided in Fig. 1-c. Cu sheets were cut into $25.4 \mathrm{~mm} \times 25.4 \mathrm{~mm}(1$ inch $\times 1$ inch) coupon and the selected surfaces for soldering were mechanically grinded using 400, 800 and Micro-cut 1200 (P2500) Grit SiC paper. Then, the surfaces were polished using $0.5 \mu \mathrm{m}$ of Alumina powder (Fig. 1-a). Sn-3.5Ag solder foil with a thickness of 50.8 micron (.002 inch) was chosen to keep the joint thickness constant. Rosin mildly activated (RMA) flux was applied on the soldering area to increase the wettability of metals and removal of oxidation. The solder foil was cut into $3 \mathrm{~mm} \times 25.4 \mathrm{~mm}$ coupon and was placed on one $\mathrm{Cu}$ coupon, facing upward (Fig. 1-a). Then, the other $\mathrm{Cu}$ coupon was placed on the top of the solder foil to form a lap joint. A spacer was kept under the top $\mathrm{Cu}$ coupon to keep it parallel and a weight of $0.1 \mathrm{~N}$ was put on the top of the solder to achieve uniform solder thickness. This amount of weight was kept constant for all test samples. After that, the specimen was put into a thermal chamber and soldered at $260^{\circ} \mathrm{C} .10 \mathrm{mins}, 30 \mathrm{mins}$ and $60 \mathrm{mins}$ of soldering time were selected to achieve different IMC thickness at different specimens. The soldered lap shear joint was kept in chamber after soldering process to cool down slowly at $\sim 2^{\circ} \mathrm{C} / \mathrm{min}$ rate.

After soldering, all specimens were machined and cut into strips of $2 \mathrm{~mm}$ thickness using wire electron discharge machine (EDM) with the dimension shown in Fig. 1-b. The sides of the stripped samples were grounded with 800 and microcut 1200 (P2500) Grit SiC paper, and polished with 
$0.5 \mu \mathrm{m}$ colloidal silica. Representative image of final specimen is provided in Fig. 1-d. Then, solution of $\mathrm{HNO}_{3}+\mathrm{H}_{2} \mathrm{O}(1: 10)$ was used to etch the bulk solder to expose the interfacial IMCs.

\subsubsection{Single Lap-Shear Test}

Single lap-shear test was performed on MTI 1000lb micro-tensile stage at room temperature. The micro-tensile tester has a maximum load capacity of $4500 \mathrm{~N}$ with a $\pm 0.2 \%$ load cell accuracy and $\pm 20 \mathrm{~nm}$ linear scale resolution. Three samples for each case were tested. The tests were displacement controlled and to understand the effects of shear strain rate, two different constant displacement rate of $0.05 \mathrm{~mm} / \mathrm{min}$ and $0.5 \mathrm{~mm} / \mathrm{min}$ were used to perform the tests. The test speed was limited due to the low camera speed which is described later in this section. This displacement rates provided a far-field or nominal shear strain rate of about $0.015 \mathrm{~s}^{-1}$ and $0.15 \mathrm{~s}^{-1}$ respectively. A preload of $5 \mathrm{~N}$ was utilized and the displacement was reset to zero when $5 \mathrm{~N}$ was reached. Loaddisplacement curves with respect to time were recorded where far-field displacement was obtained from the cross-head movement. Far field strain was calculated by dividing the crosshead displacement with the joint thickness. Cross-head displacement is the sum of the axial displacement of the $\mathrm{Cu}$ and the local shear displacement the solder, and thus it does not actually represent the local shear displacement. Therefore, it is essential to measure strain locally at the joint area. However, it is not feasible to use strain gauge and extensometer in a joint of $50 \mu \mathrm{m}$ thickness with $3 \times 2 \mathrm{~mm}$ region of interest. To observe the induced local displacements in the solder joint, an optical measuring technique was utilized (as shown in Fig. 2). A straight line normal to the solder joint was scribed $1.5 \mathrm{~mm}$ far from both joint edges covering the $\mathrm{Cu}$ substrates and solder joint with a scriber. The thickness of the scribed line was about $25 \mu \mathrm{m}$. This line thickness was very small compared to the width of the joint $(3 \mathrm{~mm})$ and assumed to have an insignificant effect on the overall shear stress-strain behavior of the joint. An optical microscope was used to monitor 
and capture the video of the changes in displacements of the scribed line while the test was running. Then, the video was analyzed by an image processing program written in Matlab to capture frames at 5 seconds interval for $0.015 \mathrm{~s}^{-1}$ tests and 1 second interval for $0.15 \mathrm{~s}^{-1}$ tests. With the help of Matlab, the captured images were converted to binary images, examined and the lateral displacements of the line were calculated for each frame and correlated with the test time (Fig. 3).

After the lap-shear test, the fracture surface characterization studies were conducted on a Scanning Electron Microscope (SEM) to investigate the failure modes and mechanism.

\section{EXPERIEMENTAL RESULTS AND DISCUSSION}

\subsection{Microstructural Investigation Of As-Fabricated Lap-Shear Solder Joints}

Cross-sectional SEM micrographs of as-reflowed specimens after bulk solder etching are provided in Fig. 4. The joint thickness for all specimens varied from 50-55 micron. The joints had three types of IMCs: $\mathrm{Cu}_{3} \mathrm{Sn}, \mathrm{Cu}_{6} \mathrm{Sn}_{5}$ and $\mathrm{Ag}_{3} \mathrm{Sn}$. A chemical analysis using energy dispersive X-ray spectroscopy (EDX) were performed to determine the IMCs (Fig. 5). Symmetrical growth of IMCs are observed in both sides for all different soldering time. At soldering time of 10 minutes, a layer of $\mathrm{Cu}_{6} \mathrm{Sn}_{5}$ with a scalloped morphology was formed. However, at 30 minutes soldering time, the $\mathrm{Cu}_{6} \mathrm{Sn}_{5}$ layer thickness tended to grow and the gaps between $\mathrm{Cu}_{6} \mathrm{Sn}_{5}$ scallops were blocked (Fig. 4-b1, b2). With further increase in soldering time to 60 minutes, the gaps between scallops were further blocked and the morphology changed from scallop type to more smooth continuous layer type (Fig. 4-c1, c2).

For 10 minutes soldering time, thin layer of $\mathrm{Cu}_{3} \mathrm{Sn}$ emerges in between $\mathrm{Cu}_{6} \mathrm{Sn}_{5} / \mathrm{Cu}$ interface. The morphology of $\mathrm{Cu}_{3} \mathrm{Sn}$ was layer type from the beginning and it got thickened with the increase in soldering time. The wavy interface of $\mathrm{Cu}_{3} \mathrm{Sn} / \mathrm{Cu}$ was uneven at 10 mins soldering time which 
mainly occurred due to different $\mathrm{Cu}$ dissolution rates at different sites. The gaps or valleys between the $\mathrm{Cu}_{6} \mathrm{Sn}_{5}$ scallops work as a fast diffusion paths due to their shorter diffusion distance and $\mathrm{Cu}$ dissolutes to bulk $\mathrm{Sn}$ at a higher rate through these scallop gaps to react with the remaining $\mathrm{Sn}$ $[14,19,20]$. Due to thicker IMC layers at higher soldering time, $\mathrm{Cu}$ dissolution rate becomes almost constant in all sites and the waviness of the $\mathrm{Cu}_{3} \mathrm{Sn} / \mathrm{Cu}$ interface vanishes.

A lot of $\mathrm{Ag}_{3} \mathrm{Sn}$ particles were dispersed in the bulk solder during soldering. For a soldering time of 10 mins, $\mathrm{Ag}_{3} \mathrm{Sn}$ was small in size. However, with the increase in soldering time, a noticeable coarsening of $\mathrm{Ag}_{3} \mathrm{Sn}$ was observed. $\mathrm{Ag}_{3} \mathrm{Sn}$ was formed as needle-like and large sheet in the joint at higher soldering time. Similar morphologies were observed for $\mathrm{Ag}_{3} \mathrm{Sn}$ for furnace cooling in other studies [21,22]. The coarsened $\mathrm{Ag}_{3} \mathrm{Sn}$ seemed to be embedded into the $\mathrm{Cu}_{6} \mathrm{Sn}_{5}$ layers (Fig. 6) and create a bridge between two opposite interfacial $\mathrm{Cu}_{6} \mathrm{Sn}_{5}$ IMC layers in some sites (fig. 4b2, fig. 4-c2).

\subsection{IMC Layer Growth Behavior}

IMC growth kinetics during solder reflow process has been studied by many researchers $[10,12,13]$. Generally, a parabolic equation of the following type is used to describe the growth kinetics of the IMCs:

$$
l_{i}=k_{i} t^{n}
$$

Here, $k_{i}$ is the IMC growth rate constant of $i$ type IMC layer and $t$ is the reaction time. Different time exponent, $n$ value, were reported for molten solders $(n=0.21-0.90)$ where a time exponent of 0.5 nicely fits with the solid-state IMC growth experimental results during the aging process. The IMC growth during aging process is due to volume diffusion mechanism. However, during soldering reflow process, the growth of IMC layers is quite complex. Some researchers reported 
the IMC growth kinetics to be governed by grain boundary (GB) diffusion and volume diffusion process $[10,13,23-25]$. It was found in literature that if the $n$ value is close to 0.33 , then the IMC growth kinetics is governed by grain boundary diffusion [23], while $n=0.5$ dictates that it is volume diffusion which controls the IMC growth [24]. To understand the IMC growth kinetics in our case, IMC thickness were examined by SEM. Images were taken at 4 different areas in each solder joint and each image covered an area of $160 \mu \mathrm{m} \times 120 \mu \mathrm{m}$. ImageJ software was utilized to select the individual IMC layers and calculated the average IMC cross-sectional surface area. This crosssectional area was then divided by the linear length of the image, as shown in the following equation to calculate the average IMC layer thickness from SEM micrograph:

$$
X=\frac{A}{L}
$$

Here, $\mathrm{A}$ is the cross-sectional surface area of the IMC layer and $\mathrm{L}$ is the linear length. Three SEM images for each soldering time were processed and the average IMC thickness with the standard deviations are documented. Fig. 7 shows the changes in average log value of thicknesses of $\mathrm{Cu}_{6} \mathrm{Sn}_{5}$, $\mathrm{Cu}_{3} \mathrm{Sn}$ IMC and the total IMC of a single interfacial side of the joint with respect to soldering time.

Table 1 provides the numerical values of total average IMC thickness in both interfacial sides. It was observed that for a soldering time of 10 mins, 30 mins and 60 mins, amount of about 40\%, $60 \%$ and $80 \%$ IMCs of total joint thickness were achieved respectively. Fig. 7 was used to calculate the $n$ value, and they were found to be $0.503,0.334$ and 0.36 for $\mathrm{Cu}_{3} \mathrm{Sn}, \mathrm{Cu}_{6} \mathrm{Sn}_{5}$ and total IMCs respectively. This values suggest that at higher soldering time, $\mathrm{Cu}_{6} \mathrm{Sn}_{5} \mathrm{IMC}$ growth is controlled by GB diffusion and growth of $\mathrm{Cu}_{3} \mathrm{Sn}$ was governed by volume diffusion mechanism. Similar findings were reported by some other researchers [26-28]. According to Yu et al. [24], at the soldering time less than $60 \mathrm{sec}$, formation and growth of IMCs are controlled by chemical reaction 
diffusion and the growth rate is very high. However, with the increase in soldering time, thick IMC layers develop which delays $\mathrm{Cu}$ diffusion to go through and hence reaction on the other side. This situation hinders chemical reaction diffusion, and volume diffusion becomes the driving mechanism.

Table 1: IMC thickness values in the joint samples

\begin{tabular}{ccc}
\hline $\begin{array}{c}\text { Soldering } \\
\text { time }\end{array}$ & $\begin{array}{c}\text { Total Average IMC thickness } \\
\text { in both interfacial sides }(\boldsymbol{\mu m})\end{array}$ & $\begin{array}{c}\text { \% of IMCs in } \\
\text { the whole joint }\end{array}$ \\
\hline 10 minutes & 20.50 & $\sim 40$ \\
30 minutes & 29.30 & $\sim 60$ \\
60 minutes & 38.45 & $\sim 80$ \\
\hline
\end{tabular}

\subsection{Shear Stress-Strain Properties And Effect Of IMC Thickness}

The shear stress-time curves obtained from the tests are shown in Fig. 8 . Shear stress was calculated by divinding the load with the solder area. A detailed comparison among those graphs disclosed several interesting observations related to the effect of the volume fraction of IMCs on the mechanical behavior of solder joints.

Volume fraction of IMCs tends to have an effect on the flow stress behavior of the joints. With the increase in IMCs from $40 \%$ to $60 \%$, flow stress seems to increase and showed higher work hardening. Work hardening in SnAg solder is reported to be largely effected by the $\mathrm{Ag}_{3} \mathrm{Sn}$ IMC particle size [29]. The $\mathrm{Ag}_{3} \mathrm{Sn}$ particles have an impeding effect on the dislocation motion. Due to their complex orthorhombic phase, dislocations that encounter these particles either bypass the obstacles by Orowan mechanism or climb over [29]. These mechanisms result in more work hardening. Therefore, joints that were fabricated at 30 mins soldering time had embedded needlelike $\mathrm{Ag}_{3} \mathrm{Sn}$ particles (Fig. 6) which more likely to increase the work hardening and thus flow stress. However, when IMC increases from $60 \%$ to $80 \%$, flow stress decreases considerably. It may be 
due to the crack propagation path which went through the $\mathrm{Cu}_{6} \mathrm{Sn}_{5} / \mathrm{Cu}_{3} \mathrm{Sn}$ interfacial layers without being effected by the $\mathrm{Ag}_{3} \mathrm{Sn}$ particles. A more detailed explanation is provided later in the article. Overall, a sensitive dependence of the flow stress on the IMC volume fraction was observed.

A sudden drop in shear stress at maximum load is an indication of sudden generation of a large crack in a brittle fracture which propagates easily due to the lower fracture toughness of brittle materials. For all test samples with various IMC fractions showed sudden drop in shear stress at maximum load point during the tests. However, very small shear stress drop were observed in the shear stress-time curves for joint samples with $40 \%$ IMCs and shear stress then gradually decreases beyond that maximum load point until it fails. This scenario likely occured due to the dominant ductile failure behavior. Small drops of load were present in several points during the tests and these may be due to the easy crack propagation through the micro-voids or brittle $\mathrm{Cu}_{6} \mathrm{Sn}_{5}$ IMC. Fractographic analysis was performed and discussed in the next section to clearify the failure modes. On the other hand, shear stress-time curves for solder joints with higher IMC thickness revealed brittle fracture mode and the ductility has diminished substantially. Large drops in shear stress at maximum point were observed for samples with higher IMC thickness.

At higher strain rate of $0.15 \mathrm{~s}^{-1}$, large shear stress drop at maximum point were apparent for all test samples. After the stress drop, samples with 40\% IMCs still showed gradual decrease in shear stress while $60 \%$ and $80 \%$ IMCs samples failed almost immidiately. Therfore, sensitive dependence of the shear stress-strain behavior on the volume fraction of IMCs is more evident at higher strain rate.

Fig. 9 shows the plots of shear strain vs. time for both $0.015 \mathrm{~s}^{-1}$ and $0.15 \mathrm{~s}^{-1}$ shear strain rates. Farfield shear strain is constant with the time as it was prescribed during the experimental setup. However, local shear strain at the solder joint area seemed to deviate significantly from the far- 
field shear strain. It can be seen that, for all tests, initially at the same test time, the difference between far-field shear strain and local shear strain is very high (region 1 in Fig. 9). This may indicate that at this period, elastic deformation of $\mathrm{Cu}$ and/or fixture tolerance and displacement contribute to the major portion of the far-field or crosshead displacement. After that, the local shear deformation in solder region develops with time and local shear strain rate becomes similar to farfield shear strain rate (similar slope of far-field and local shear strain curve-region 2 in Fig. 9). Similar observations were reported in some literature [30,31]. It can be observed in Fig. 9 that, $60 \%$ and $80 \%$ IMC samples start to deform at a higher local shear strain rate earlier than $40 \%$ IMC samples when the tests were conducted at $0.15 \mathrm{~s}^{-1}$ shear strain rate. At higher shear strain rate, the high volume fraction of hard and brittle IMCs might induced higher local stresses in the bulk solder region which contributed to early local deformation. At lower shear strain rate, this effect might not be significant due to sufficient available time for stress relaxation. Overall, the figure provides an idea on how the local shear strain evolves with time when solder joints have different IMC thickness.

Experimental shear stresses vs. local shear strains for selected samples with different IMC thickness were plotted in Fig. 10 to compare their shear behavior. Apparently, with increasing volume fraction of IMCs, the solder exhibits a higher stiffness (Fig. 10-a,b). This is true for both shear strain rate cases. Shear stiffness of IMCs are higher than that of bulk solder [32-34]. Therefore, as the volume fraction of IMCs increase from $40 \%$ to $60 \%$ and $80 \%$, solder tends to provide a stiffer response.

Fig. 11 shows the effect of variation in IMC volume fraction on ultimate shear strength and strain to failure (fracture strain) at $0.015 \mathrm{~s}^{-1}$ and $0.15 \mathrm{~s}^{-1}$ strain rate. It can be seen that with the increase in the volume fraction of IMCs from $40 \%$ to $60 \%$, ultimate shear strength increases significantly 
(from $16 \mathrm{MPa}$ to $24 \mathrm{MPa}$ for $0.015 \mathrm{~s}^{-1} ; 20 \mathrm{MPa}$ to $25 \mathrm{MPa}$ for $0.15 \mathrm{~s}^{-1}$ ). Recently, several researchers reported similar observation while analyzing joints with various IMC thickness $[11,12,35]$. These hard and brittle IMCs resist shearing at the beginning of plastic flow. So, with higher IMC thickness, resistance to the initial shear deformation increases and shear stress increases considerably. Local images captured during the tests for 60\% IMCs samples showed that major portion of the cracks propagated through and partially broke $\mathrm{Cu}_{6} \mathrm{Sn}_{5}$ IMC (Fig. 12-b). However, a decrease in shear strength was witnessed when 60\% IMCs and 80\% IMCs sample were compared although the shear strength value was still higher than the shear strength of $40 \%$ IMCs joints. Similar trend in the correlation between shear strength and IMC layer thickness was reported recently by Xing et al. [36] for $\mathrm{Zn}-\mathrm{Sn}-\mathrm{Cu}-\mathrm{Bi} / \mathrm{Cu}$ solder joint. They observed an initial increase in shear strength when IMC layer thickness increased. However, shear strength was observed to deteriorate quickly with the continuous increase in IMC thickness. In our study, it has been observed during the in situ tests that cracks propagated through $\mathrm{Cu}_{6} \mathrm{Sn}_{5} / \mathrm{Cu}_{3} \mathrm{Sn}$ interface for 80\% IMCs joint (Fig. 12-c). With 60 mins soldering time, the joints developed a thicker planar $\mathrm{Cu}_{3} \mathrm{Sn} / \mathrm{Cu}_{6} \mathrm{Sn}_{5}$ interfacial layer (Fig. 4-c1, c2). This interfacial $\mathrm{Cu}_{3} \mathrm{Sn}_{2} / \mathrm{Cu}_{6} \mathrm{Sn}_{5}$ planar layer tends to be an easy fracture path by delamination [37]. As, the interfacial layer of $\mathrm{Cu}_{3} \mathrm{Sn} / \mathrm{Cu}_{6} \mathrm{Sn}_{5}$ was wavy and thin for joints fabricated with 30 mins soldering time, it resisted the crack propagation and delamination of the interfacial $\mathrm{Cu}_{3} \mathrm{Sn} / \mathrm{Cu}_{6} \mathrm{Sn}_{5}$ layer (Fig. 4-b1, b2). The above observation promotes the necessity of including $\mathrm{Cu}_{3} \mathrm{Sn} / \mathrm{Cu}_{6} \mathrm{Sn}_{5}$ interfacial delamination as a major failure mode criteria when a thicker planar $\mathrm{Cu}_{3} \mathrm{Sn}$ layer is present in the joint after fabrication.

Strain at failure was measured from the final lateral displacement of the scribed line and dividing it by the total joint thickness. Strain at failure seemed to be affected by the volume fraction of IMCs. A significant reduction in failure strain was observed when the IMC thickness was 
increased. Also, 40\% IMCs joints exhibited highest failure strain due to the ductility provided by bulk solder which controlled the failure mode. For higher IMC thickness joints, the failure mode was controlled by IMCs. As, it is known that hard and brittle materials assist crack propagation due to their lower fracture toughness, when cracks initiate at high IMC thickness samples it propagates through the IMCs which is a faster fracture path and fails at lower shear strain.

Shear strain rate has a profound effect on the shear properties in solder joints $[38,39]$. At higher shear strain rate, shear strength increases for all test samples with the increase in IMC thickness although the increase is noticeable for $40 \%$ IMC joint samples but the increase for $60 \%$ IMC and 80\% IMC joint samples were insignificant (Fig. 11-a). Overall, the shear strengths are not largely effected by the shear strain rates at this level. Experiments need to be conducted at higher shear strain rates to investigate their effect on shear strength.

For both $0.015 \mathrm{~s}^{-1}$, and $0.15 \mathrm{~s}^{-1}$ shear strain rate, the strain to failure decreases with the increase in the IMC volume fraction (Fig. 11-b). Higher shear strain rate reduced the strain to failure significantly for $40 \%$ IMC joints. With the increase in shear strain rate, ductile to brittle failure mode transformation was evident during the fractography analysis described in the next section. Brittle failure provided lower failure strain where higher failure strain was found due to ductile failure at lower shear strain rate. The effect of shear strain rates on the joints with $80 \%$ IMCs was not noticed as brittle failure mode was evident in both cases, providing almost similar strain to failure. Further detailed discussion is provided in the fractography analysis section.

\subsection{Fractography Analysis of The Fracture Surfaces}

There are five probable fracture paths that a primarily interfacial crack may follow to eventually cause failure of the joint. These paths are: (a) through the solder, (b) along solder/ $\mathrm{Cu}_{6} \mathrm{Sn}_{5}$ interface, 
(c) through $\mathrm{Cu}_{6} \mathrm{Sn}_{5} \mathrm{IMC}$, (d) along the $\mathrm{Cu}_{6} \mathrm{Sn}_{5} / \mathrm{Cu}_{3} \mathrm{Sn}$ interface, and (e) through $\mathrm{Cu}_{3} \mathrm{Sn}$ [40]. Cracks may also move in between these proposed paths. In thicker solder joints, the most common fracture modes are through the solder, along $\mathrm{Cu}_{6} \mathrm{Sn}_{5} /$ solder interface or through $\mathrm{Cu}_{6} \mathrm{Sn}_{5}$ IMC [40]. The others are not prevalent. However, thinner joints also add the other mechanisms, especially when the joint has a high volume fraction of IMCs [40]. Fig. 12 shows the representative crack path propagation sites optically captured during in situ tests for samples with $40 \%, 60 \%$, and $80 \%$ IMCs.

Fractography analysis were conducted after the single lap-shear tests in order to understand the failure mechanism for high IMC thickness joint samples. Fig. 13 shows the failure surfaces of the joints at $0.015 \mathrm{~s}^{-1}$, where Fig. 14 has the failure surface images of the joints at $0.15 \mathrm{~s}^{-1}$. At $40 \%$ IMCs joints with $0.015 \mathrm{~s}^{-1}$ shear strain rate, fracture surface smearing along the loading direction is highly evident (Fig. 13-a). Similar observation was reported by Deng et al. during lap-shear tests [41]. Moreover, exposed $\mathrm{Cu}_{6} \mathrm{Sn}_{5} \mathrm{IMC}$ are observed in the smeared fracture surfaces. $\mathrm{Cu}_{6} \mathrm{Sn}_{5}$ nodule tips protrude on the fracture surface due to a combination of low fracture toughness of $\mathrm{Cu}_{6} \mathrm{Sn}_{5}$ and the local strain concentration on the $\mathrm{Cu}_{6} \mathrm{Sn}_{5} /$ solder interfaces [42]. Optical microscopic image provided at Fig. 12-a also gives an impression of the crack propagation which was mostly along the soft solder region. These suggest that the solder joints failed with a ductile fracture mode and crack propagated through the bulk solder. For solder joints with $60 \%$ IMCs at $0.015 \mathrm{~s}^{-1}$, there still exists some fracture surface smearing along the shear direction, although the exposed $\mathrm{Cu}_{6} \mathrm{Sn}_{5}$ amount is higher in this case (Fig. 13-b). There are some broken $\mathrm{Cu}_{6} \mathrm{Sn}_{5}$ IMCs observed at the fracture surface. Also, optical image taken during the tests showed crack propagation along solder/ $\mathrm{Cu}_{6} \mathrm{Sn}_{5}$ interface with some broken $\mathrm{Cu}_{6} \mathrm{Sn}_{5}$ IMCs (Fig. 12-b). These observation depicts that failure occurred mostly along solder/ $\mathrm{Cu}_{6} \mathrm{Sn}_{5}$ interface, providing a ductile-brittle mixed failure 
mode. On the other hand, SEM fractograph of fracture surfaces of solder joints with $80 \%$ IMCs at $0.015 \mathrm{~s}^{-1}$ portray an interesting failure mode (Fig. 13-c1, c2). EDX analysis provided a significantly higher $\mathrm{Cu}$ picks at the exposed area pointed at target 2 in the Fig. 13-c1. This suggests that the sampling region is possibly $\mathrm{Cu}_{3} \mathrm{Sn}$ layer. Transition ridges at which the fracture shifted to the $\mathrm{Cu}_{6} \mathrm{Sn}_{5} / \mathrm{Cu}_{3} \mathrm{Sn}$ interface, with exposed $\mathrm{Cu}_{3} \mathrm{Sn}$ was observed (Fig. 13-c1). There are few intact $\mathrm{Cu}_{6} \mathrm{Sn}_{5}$ near to the transitional ridge. A magnified image of fracture surface provides a view of micro cracks on the $\mathrm{Cu}_{3} \mathrm{Sn}$ surface (Fig. 13-c2). In these samples, the cracks tend to frequently transited between the two opposite $\mathrm{Cu}_{6} \mathrm{Sn}_{5} / \mathrm{Cu}_{3} \mathrm{Sn}$ interfaces. Optical microscopic image of crack propagation provided at fig. 12-c also showed the transition of crack path between two opposite $\mathrm{Cu}_{6} \mathrm{Sn}_{5} / \mathrm{Cu}_{3} \mathrm{Sn}$ interfaces. This crack transition may be largely activated by the brittle $\mathrm{Ag}_{3} \mathrm{Sn}$ sheets that made a bridge between two interfacial sides (Fig. 4-b2, c2). From Fig. 4-c1,c2 it was seen that $\mathrm{Cu}_{3} \mathrm{Sn}$ layer was mostly thicker and planar for joints fabricated at 60 mins soldering time. In this case, apparently $\mathrm{Cu}_{6} \mathrm{Sn}_{5} / \mathrm{Cu}_{3} \mathrm{Sn}$ interface delamination dominates the failure mechanism. It was reported by Hayes et al. [37] that when joints had higher percentage of $\mathrm{Cu}_{3} \mathrm{Sn}$, interfacial delamination between $\mathrm{Cu}_{3} \mathrm{Sn} / \mathrm{Cu}_{6} \mathrm{Sn}_{5}$ layer may dominate due to its relatively lower fracture toughness. Overall, although the joints had a very high percentage of $\mathrm{Cu}_{6} \mathrm{Sn}_{5}$, thickness of $\mathrm{Cu}_{3} \mathrm{Sn}$ and morphology of $\mathrm{Cu}_{3} \mathrm{Sn} / \mathrm{Cu}_{6} \mathrm{Sn}_{5}$ interfacial layer tends to control the failure site.

SEM Fractograph images for samples investigated at $0.15 \mathrm{~s}^{-1}$ shear strain rate is provided in Fig. 14. Fractography analysis at samples with $40 \%$ IMCs showed ductile region with elongated dimples; although this time, the exposed $\mathrm{Cu}_{6} \mathrm{Sn}_{5}$ amount was higher and the dimples were either very small or very large (Fig. 14-a). The amount of shear smearing at bulk solder was also less than samples with $40 \%$ IMCs tested at lower shear strain rate. Samples with $60 \%$ IMCs showed brittle fracture regions with transition ridges from solder to IMC (Fig. 14-b). It had both exposed 
$\mathrm{Cu}_{6} \mathrm{Sn}_{5}$ and $\mathrm{Cu}_{3} \mathrm{Sn}$ regions. Similarly, $80 \%$ IMCs joint samples showed almost identical fracture surfaces with brittle regions and exposed IMCs. Overall, at higher shear strain, joints with higher volume fraction of IMCs showed mostly brittle fracture mode.

The trend observed from the shear stress-strain behavior and fractography analysis suggests that fracture behavior of the joints largely dependent on the volume fraction of IMCs. A schematic diagram of possible fracture path is shown in Fig. 15. When IMC volume fraction is less than the bulk solder volume fraction, failure mode tends to be controlled by bulk solder region and ductile fracture is being dominated. However, when IMC volume fraction is larger than bulk solder volume fraction, the failure mode is largely dominated by the IMC presence and morphology. When a solder joint has a thick $\mathrm{Cu}_{3} \mathrm{Sn}$ with planar $\mathrm{Cu}_{3} \mathrm{Sn} / \mathrm{Cu}_{6} \mathrm{Sn}_{5}$ interfacial layer, the joint tends to fail due to the $\mathrm{Cu}_{3} \mathrm{Sn} / \mathrm{Cu}_{6} \mathrm{Sn}_{5}$ interfacial delamination.

\section{SUMMARY AND CONCLUSIONS}

The shear stress-strain and fracture behavior of $\mathrm{Sn}-3.5 \mathrm{Ag} / \mathrm{Cu}$ solder joints with $50 \mu \mathrm{m}$ thickness were investigated in this study. Different volume fraction of IMCs were achieved by fabricating samples with different soldering time at $260^{\circ} \mathrm{C}$ soldering temperature. The effect of IMC volume fraction on the shear behavior of the solder joints were then investigated using a single lap-shear test with two different shear strain rates. An optical measurement technique, along with developed image processing computer program was used to investigate the local shear strain behavior at solder region. Cross-sectional observations of the joint samples revealed different IMC thickness and morphology at different soldering time. The study and findings is summarized here:

- With the increase in volume fraction of IMCs from $40 \%$ to $60 \%$, a large increase in shear strength was observed. On the other hand, when volume fraction of IMCs was $80 \%$ with a 
thick layer of $\mathrm{Cu}_{3} \mathrm{Sn}$, a decrease in shear strength was observed although it was still higher than the shear strength of $40 \%$ IMCs joints.

- Local shear strain behavior was completely different than far-field shear strain behavior due to the role of elastic deformation of $\mathrm{Cu}$ substrate. Therefore, care should be taken during the shear behavior analysis to investigate the micro-scale solder joints.

- With increasing volume fraction of IMCs in the solder joints, an apparent stiffer shear response was observed. This may be due to the higher shear modulus of IMCs compared to the bulk solder.

- Strain to failure is greatly affected by the presence of IMCs in the solder joint. With the increase of IMC thickness, strain to failure tends to decrease consistently. The rate of decrease was higher for low shear strain rate compared to the decrease rate for higher shear strain rate.

- Fractography analysis suggests that when a solder joint had higher volume fraction of bulk solder, fracture behavior was dominated by solder with ductile failure mode. However, when joint had higher volume fraction of IMCs, brittle fracture mode was evident and largely controlled by IMC morphology.

\section{ACKNOWLEDGEMENTS}

The authors would like to acknowledge the National Science Foundation (CMMI Grant No. 1416682) for providing the financial support of this research. Authors would like to acknowledge the help of Mr. Adam Wentworth of Material Science Engineering department and Mr. Mark Biron of C2E2 in fabricating the specimens. 


\section{REFERENCES}

[1] I. Panchenko, K. Croes, I. De Wolf, J. De Messemaeker, E. Beyne, K.-J. Wolter, Degradation of Cu6Sn5 intermetallic compound by pore formation in solid-liquid interdiffusion $\mathrm{Cu} / \mathrm{Sn}$ microbump interconnects, Microelectron. Eng. 117 (2014) 26-34. doi:10.1016/j.mee.2013.12.003.

[2] O.M. Abdelhadi, L. Ladani, Effect of Joint Size on Microstructure and Growth Kinetics of Intermetallic Compounds in Solid-Liquid Interdiffusion Sn3.5Ag/Cu-Substrate Solder Joints, J. Electron. Packag. 135 (2013) 021004. doi:10.1115/1.4023846.

[3] L. Yang, Z.F. Zhang, Growth Behavior of Intermetallic Compounds in $\mathrm{Cu} / \mathrm{Sn} 3.0 \mathrm{Ag} 0.5 \mathrm{Cu}$ Solder Joints with Different Rates of Cooling, J. Electron. Mater. 44 (2014) 590-596. doi:10.1007/s11664-014-3530-6.

[4] S.W.O.N. Jeong, J.H. Kim, H.M.O. Lee, Effect of cooling rate on growth of the intermetallic compound and fracture mode of near-eutectic $\mathrm{Sn}-\mathrm{Ag}-\mathrm{Cu} / \mathrm{Cu}$ pad: Before and after aging, J. Electron. Mater. 33 (2004) 1530-1544. doi:10.1007/s11664-004-0095-9.

[5] Q.K. Zhang, W.M. Long, Z.F. Zhang, Growth behavior of intermetallic compounds at $\mathrm{Sn}-\mathrm{Ag} / \mathrm{Cu}$ joint interfaces revealed by 3D imaging, J. Alloys Compd. 646 (2015) 405411. doi:10.1016/j.jallcom.2015.05.271.

[6] S.F. Choudhury, L. Ladani, Grain Growth Orientation and Anisotropy in Cu6Sn5 Intermetallic: Nanoindentation and Electron Backscatter Diffraction Analysis, J. Electron. Mater. 43 (2014) 996-1004. doi:10.1007/s11664-014-2977-9.

[7] S.F. Choudhury, L. Ladani, Effect of Intermetallic Compounds on the Thermomechanical Fatigue Life of Three-Dimensional Integrated Circuit Package Microsolder Bumps: Finite Element Analysis and Study, J. Electron. Packag. 137 (2015) 041003. doi:10.1115/1.4031523.

[8] L. Zhang, S.B. Xue, G. Zeng, L.L. Gao, H. Ye, Interface reaction between $\mathrm{SnAgCu} / \mathrm{SnAgCuCe}$ solders and $\mathrm{Cu}$ substrate subjected to thermal cycling and isothermal aging, J. Alloys Compd. 510 (2012) 38-45. doi:10.1016/j.jallcom.2011.08.044.

[9] H. Li, R. An, C. Wang, Z. Jiang, In situ quantitative study of microstructural evolution at the interface of $\mathrm{Sn} 3.0 \mathrm{Ag} 0.5 \mathrm{Cu} / \mathrm{Cu}$ solder joint during solid state aging, J. Alloys Compd. 634 (2015) 94-98. doi:10.1016/j.jallcom.2015.02.088.

[10] P. Liu, P. Yao, J. Liu, Effects of multiple reflows on interfacial reaction and shear strength of $\mathrm{SnAgCu}$ and $\mathrm{SnPb}$ solder joints with different PCB surface finishes, J. Alloys Compd. 470 (2009) 188-194. doi:10.1016/j.jallcom.2008.02.102.

[11] Y. Goh, A.S.M.A. Haseeb, H.L. Liew, M.F.M. Sabri, Deformation and fracture behaviour of electroplated Sn-Bi/Cu solder joints, J. Mater. Sci. 50 (2015) 4258-4269. doi:10.1007/s10853-015-8978-0.

[12] K.N. Bhat, K.N. Prabhu, Satyanarayan, Effect of reflow temperature and substrate roughness on wettability, IMC growth and shear strength of SAC387/Cu bonds, J. Mater. Sci. Mater. Electron. 25 (2014) 864-872. doi:10.1007/s10854-013-1658-4. 
[13] S.M.L. Nai, J. Wei, M. Gupta, Interfacial intermetallic growth and shear strength of leadfree composite solder joints, J. Alloys Compd. 473 (2009) 100-106.

doi:10.1016/j.jallcom.2008.05.070.

[14] X. Hu, Y. Li, Y.Y. Liu, Y.Y. Liu, Z. Min, Microstructure and shear strength of $\mathrm{Sn} 37 \mathrm{~Pb} / \mathrm{Cu}$ solder joints subjected to isothermal aging, Microelectron. Reliab. 54 (2014) 1575-1582. doi:10.1016/j.microrel.2014.04.003.

[15] Y.J. Chen, C.K. Chung, C.R. Yang, C.R. Kao, Single-joint shear strength of micro Cu pillar solder bumps with different amounts of intermetallics, Microelectron. Reliab. 53 (2013) 47-52. doi:10.1016/j.microrel.2012.06.116.

[16] M. Sona, K.N. Prabhu, The effect of reflow time on reactive wetting, evolution of interfacial IMCs and shear strength of eutectic Sn-Cu solder alloy, J. Mater. Sci. Mater. Electron. 25 (2014) 1446-1455. doi:10.1007/s10854-014-1749-X.

[17] Q.S. Zhu, J.J. Guo, P.J. Shang, Z.G. Wang, J.K. Shang, Effects of aging on interfacial microstructure and reliability between $\mathrm{SnAgCu}$ solder and $\mathrm{FeNi} / \mathrm{Cu} \mathrm{UBM}, \mathrm{Adv}$. Eng. Mater. 12 (2010) 497-503. doi:10.1002/adem.200900294.

[18] C. Chen, L. Zhang, J. Zhao, L. Cao, J.K. Shang, Gap Size Effects on the Shear Strength of $\mathrm{Sn} / \mathrm{Cu}$ and Sn/FeNi Solder Joints, J. Electron. Mater. 41 (2012) 2487-2494. doi:10.1007/s11664-012-2156-9.

[19] X. Deng, G. Piotrowski, J.J. Williams, N. Chawla, Influence of initial morphology and thickness of Cu6Sn5 and Cu3Sn intermetallics on growth and evolution during thermal aging of Sn-Ag solder/Cu joints, J. Electron. Mater. 32 (2003) 1403-1413. doi:10.1007/s11664-003-0108-0.

[20] W.-L. Chiu, C.-M. Liu, Y.-S. Haung, C. Chen, Formation of plate-like channels in $\mathrm{Cu} 6 \mathrm{Sn} 5$ and $\mathrm{Cu} 3 \mathrm{Sn}$ intermetallic compounds during transient liquid reaction of $\mathrm{Cu} / \mathrm{Sn} / \mathrm{Cu}$ structures, Mater. Lett. 164 (2016) 5-8. doi:10.1016/j.matlet.2015.10.056.

[21] L.C. Tsao, Evolution of nano-Ag3Sn particle formation on $\mathrm{Cu}-\mathrm{Sn}$ intermetallic compounds of $\mathrm{Sn} 3.5 \mathrm{Ag} 0.5 \mathrm{Cu}$ composite solder/Cu during soldering, J. Alloys Compd. 509 (2011) 2326-2333. doi:10.1016/j.jallcom.2010.11.010.

[22] L. Qu, H. Ma, H. Zhao, N. Zhao, A. Kunwar, M. Huang, The nucleation of Ag3Sn and the growth orientation relationships with Cu6Sn5, in: 2013 14th Int. Conf. Electron. Packag. Technol., IEEE, 2013: pp. 377-381. doi:10.1109/ICEPT.2013.6756493.

[23] M. Schaefer, R.A. Fournelle, J. Liang, Theory for intermetallic phase growth between cu and liquid $\mathrm{Sn}-\mathrm{Pb}$ solder based on grain boundary diffusion control, J. Electron. Mater. 27 (1998) 1167-1176. doi:10.1007/s11664-998-0066-7.

[24] D.Q. Yu, L. Wang, The growth and roughness evolution of intermetallic compounds of $\mathrm{Sn}-\mathrm{Ag}-\mathrm{Cu} / \mathrm{Cu}$ interface during soldering reaction, J. Alloys Compd. 458 (2008) 542-547. doi:10.1016/j.jallcom.2007.04.047.

[25] O.M. Abdelhadi, L. Ladani, IMC growth of $\mathrm{Sn}-3.5 \mathrm{Ag} / \mathrm{Cu}$ system: Combined chemical reaction and diffusion mechanisms, J. Alloys Compd. 537 (2012) 87-99. doi:10.1016/j.jallcom.2012.04.068. 
[26] R.A. Gagliano, M.E. Fine, Thickening kinetics of interfacial Cu6Sn5 and Cu3Sn layers during reaction of liquid tin with solid copper, J. Electron. Mater. 32 (2003) 1441-1447. doi:10.1007/s11664-003-0113-3.

[27] M.S. Park, M.K. Stephenson, C. Shannon, L.A. Cáceres Díaz, K.A. Hudspeth, S.L. Gibbons, et al., Experimental and computational study of the morphological evolution of intermetallic compound (Cu6Sn5) layers at the $\mathrm{Cu} / \mathrm{Sn}$ interface under isothermal soldering conditions, Acta Mater. 60 (2012) 5125-5134. doi:10.1016/j.actamat.2012.06.008.

[28] J. Görlich, G. Schmitz, K.N. Tu, On the mechanism of the binary Cu/Sn solder reaction, Appl. Phys. Lett. 86 (2005) 053106. doi:10.1063/1.1852724.

[29] T.-K. Lee, T.R. Bieler, C.-U. Kim, H. Ma, Fundamentals of Lead-Free Solder Interconnect Technology: From Microstructures to Reliability, Springer, 2014.

[30] N. Chawla, Y.-L. Shen, X. Deng, E.S. Ege, An evaluation of the lap-shear test for Sn-rich solder/Cu couples: Experiments and simulation, J. Electron. Mater. 33 (2004) 1589-1595. doi:10.1007/s11664-004-0102-1.

[31] Y.-L. Shen, N. Chawla, E.S. Ege, X. Deng, Deformation analysis of lap-shear testing of solder joints, Acta Mater. 53 (2005) 2633-2642. doi:10.1016/j.actamat.2005.02.024.

[32] S.F. Choudhury, L. Ladani, Single Crystal Plasticity Finite Element Analysis of Cu6Sn5 Intermetallic, Metall. Mater. Trans. A. 46 (2014) 1108-1118. doi:10.1007/s11661-0142696-0.

[33] G. Ghosh, Elastic properties, hardness, and indentation fracture toughness of intermetallics relevant to electronic packaging, J. Mater. Res. 19 (2004) 1439-1454.

[34] Wen-Hwa Chen, Hsien-Chie Cheng, Ching-Feng Yu, On the mechanical properties of $\mathrm{Cu} 3 \mathrm{Sn}$ intermetallic compound through molecular dynamics simulation and nanoindentation testing, in: 2010 11th Int. Therm. Mech. Multi-Physics Simulation, Exp. Microelectron. Microsystems, IEEE, 2010: pp. 1-7. doi:10.1109/ESIME.2010.5464610.

[35] C. Yang, F. Song, S.W.R. Lee, Effect of interfacial strength between Cu6Sn5 and Cu3Sn intermetallics on the brittle fracture failure of lead-free solder joints with OSP pad finish, in: 2011 IEEE 61st Electron. Components Technol. Conf., IEEE, 2011: pp. 971-978. doi:10.1109/ECTC.2011.5898627.

[36] F. Xing, J. Yao, J. Liang, X. Qiu, Influence of intermetallic growth on the mechanical properties of $\mathrm{Zn}-\mathrm{Sn}-\mathrm{Cu}-\mathrm{Bi} / \mathrm{Cu}$ solder joints, J. Alloys Compd. 649 (2015) 1053-1059. doi:10.1016/j.jallcom.2015.07.231.

[37] S.M. Hayes, N. Chawla, D.R. Frear, Interfacial fracture toughness of Pb-free solders, Microelectron. Reliab. 49 (2009) 269-287. doi:10.1016/j.microrel.2008.11.004.

[38] J.H.L. Pang, T.H. Low, B.S. Xiong, X. Luhua, C.C. Neo, Thermal cycling aging effects on $\mathrm{Sn}-\mathrm{Ag}-\mathrm{Cu}$ solder joint microstructure, IMC and strength, Thin Solid Films. 462-463 (2004) 370-375. doi:10.1016/j.tsf.2004.05.092.

[39] H. Rhee, K.N. Subramanian, A. Lee, J.G. Lee, Mechanical characterization of Sn-3.5Ag solder joints at various temperatures, Solder. Surf. Mt. Technol. 15 (2003) 4-21. 
[40] B. Talebanpour, Z. Huang, Z. Chen, I. Dutta, Effect of Joint Scale and Processing on the Fracture of Sn-3Ag-0.5Cu Solder Joints: Application to Micro-bumps in 3D Packages, J. Electron. Mater. (2015). doi:10.1007/s11664-015-4066-0.

[41] X. Deng, R.S. Sidhu, P. Johnson, N. Chawla, Influence of Reflow and Thermal Aging on the Shear Strength and Fracture Behavior of Sn-3 . 5Ag Solder / Cu Joints, Matallurgical Mater. Trans. A. 36 (2005) 55-64.

[42] H.-T. Lee, M.-H. Chen, H.-M. Jao, T.-L. Liao, Influence of interfacial intermetallic compound on fracture behavior of solder joints, Mater. Sci. Eng. A. 358 (2003) 134-141. doi:10.1016/S0921-5093(03)00277-6. 

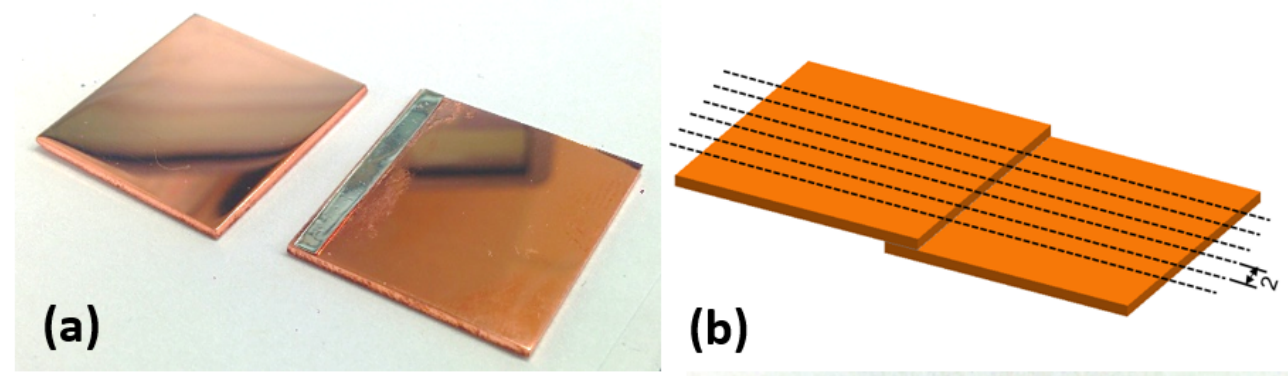

(b)
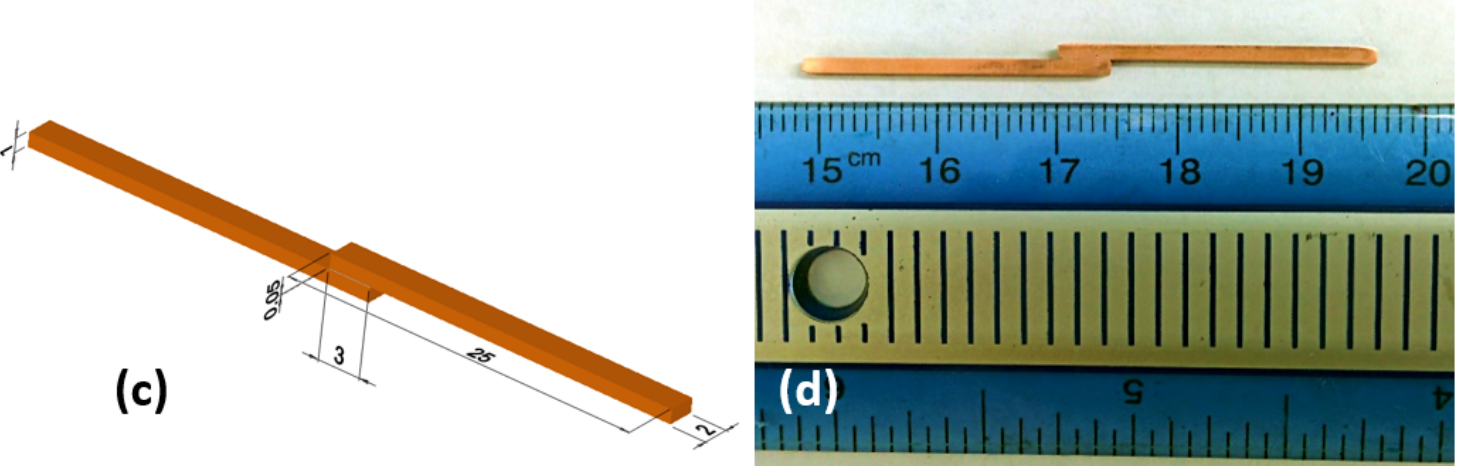

Fig. 1: (a) Actual $\mathrm{Cu}$ coupon with solder foil on one side, (b) Fabricated specimens were stripped using wire EDM, (c) the dimensions and (d) figure of actual sample for single lap-shear test

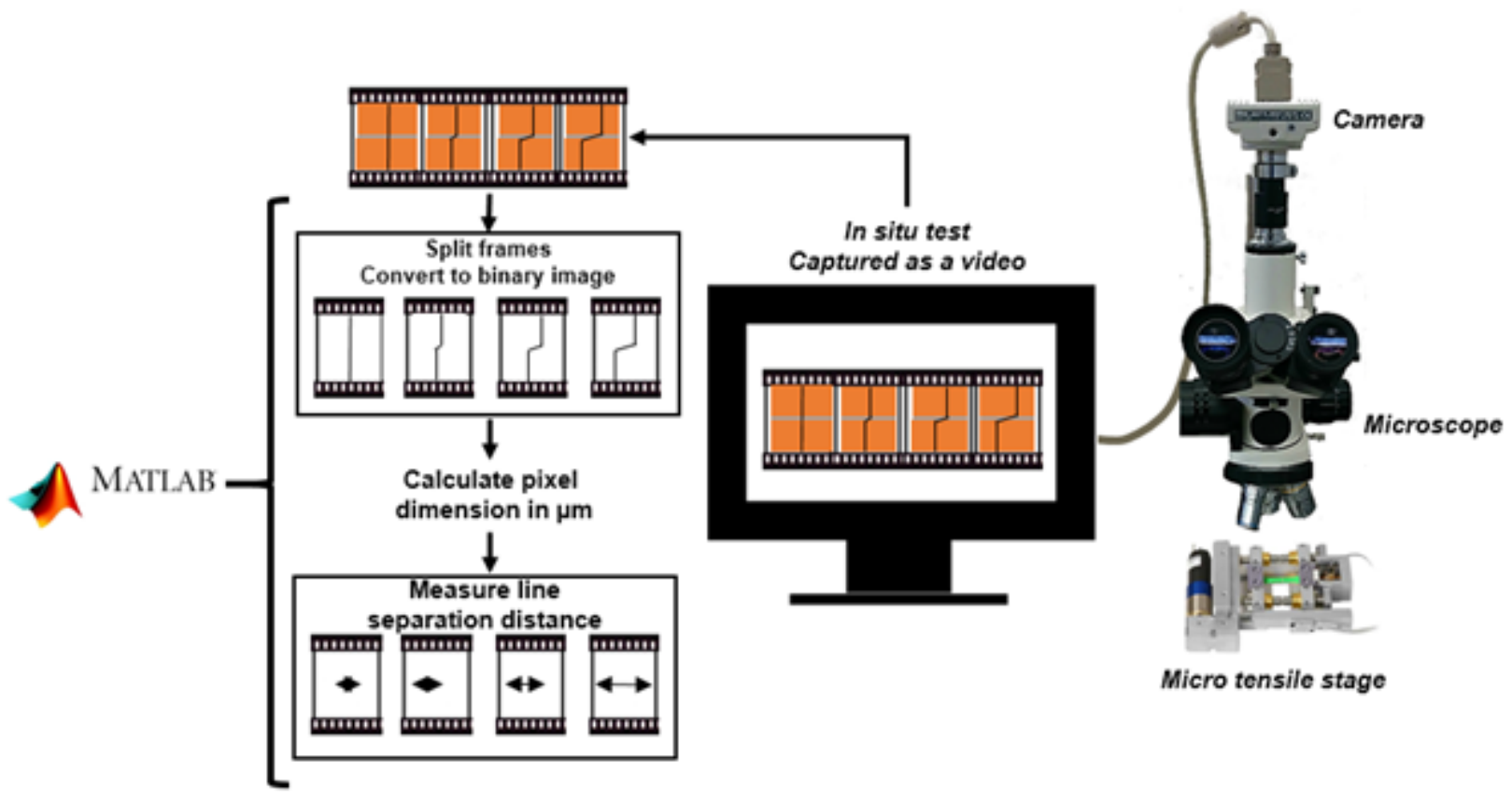

Fig. 2 : Process flow of measuring local displacements in single lap-shear test 

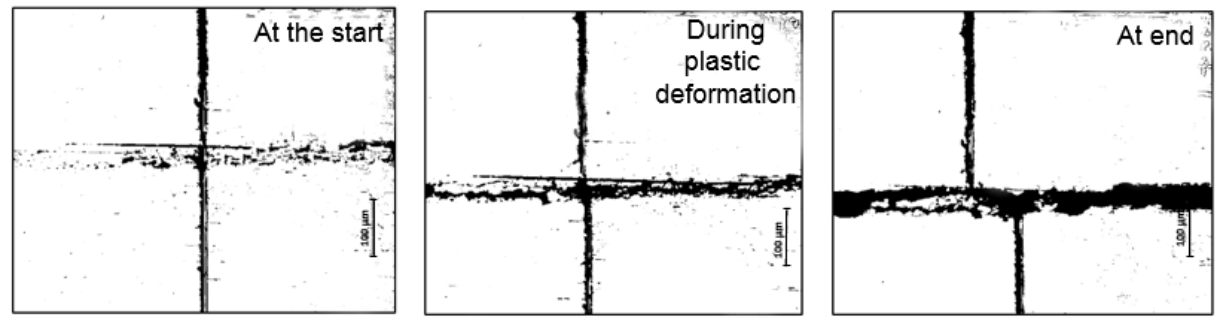

Fig. 3: Representative binary images taken from the captured test video and these are used to calculate the axial displacements of the scribed line.

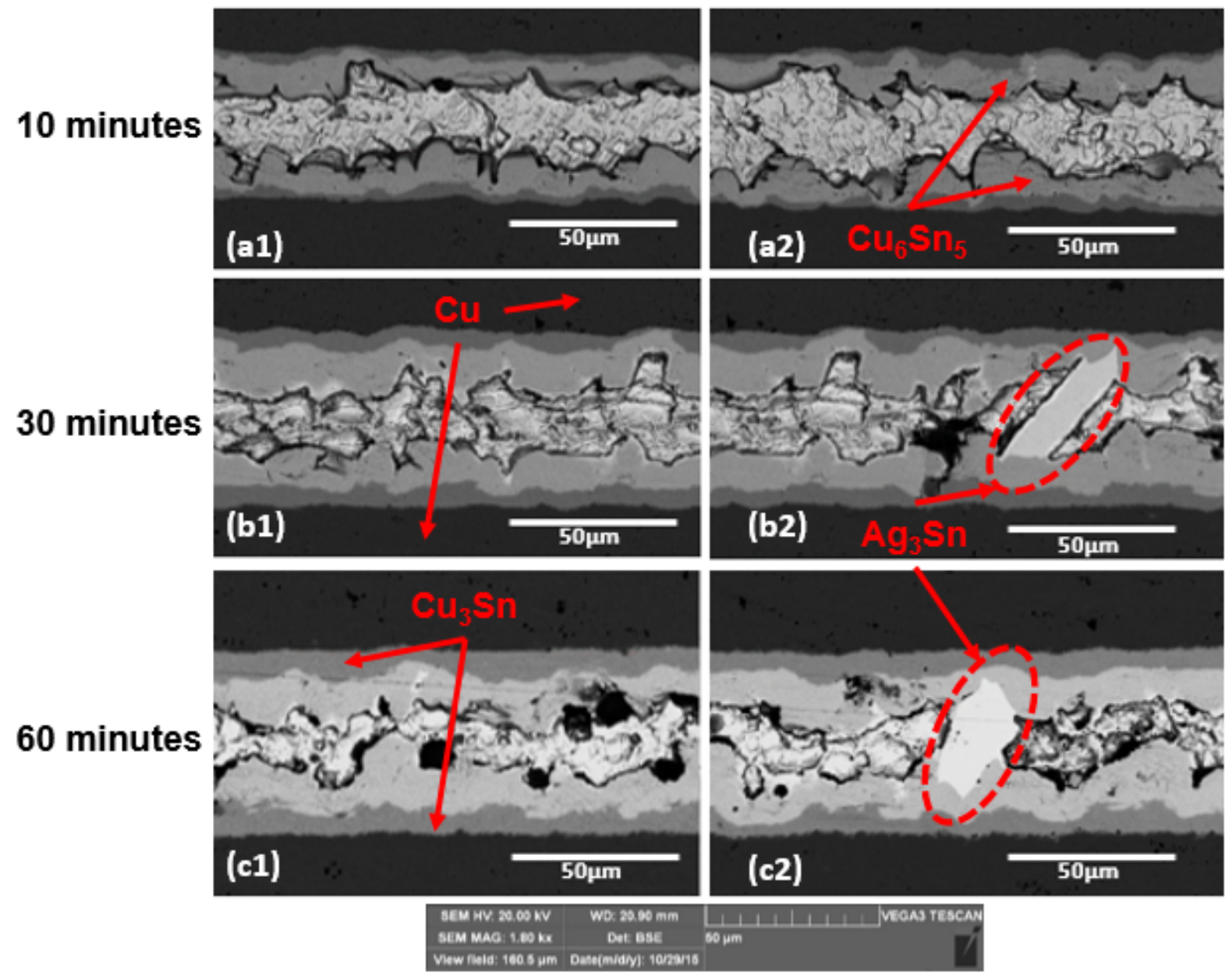

Fig. 4: Cross sectional micrographs of the solder joints after soldering process at a temperature of $260^{\circ} \mathrm{C}$ and soldering time of (a) 10 minutes, (b) 30 minutes and (c) 60 minutes. 

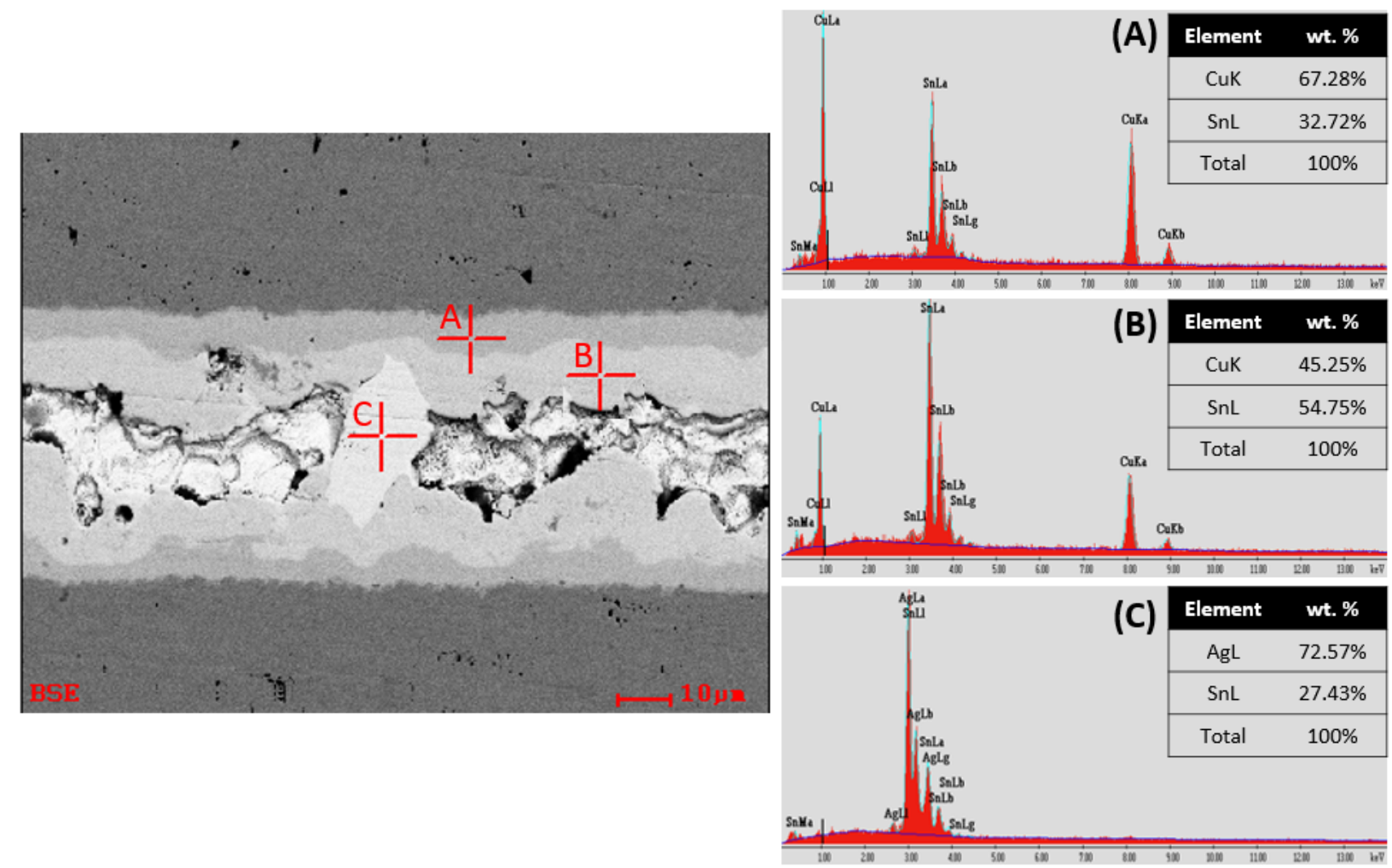

Fig. 5: EDX analysis of the $\mathrm{Sn}-3.5 \mathrm{Ag} / \mathrm{Cu}$ solder joints indicating the presence of (a) $\mathrm{Cu}_{3} \mathrm{Sn}$, (b) $\mathrm{Cu}_{6} \mathrm{Sn}_{5}$ and (c) $\mathrm{Ag}_{3} \mathrm{Sn}$ IMCs

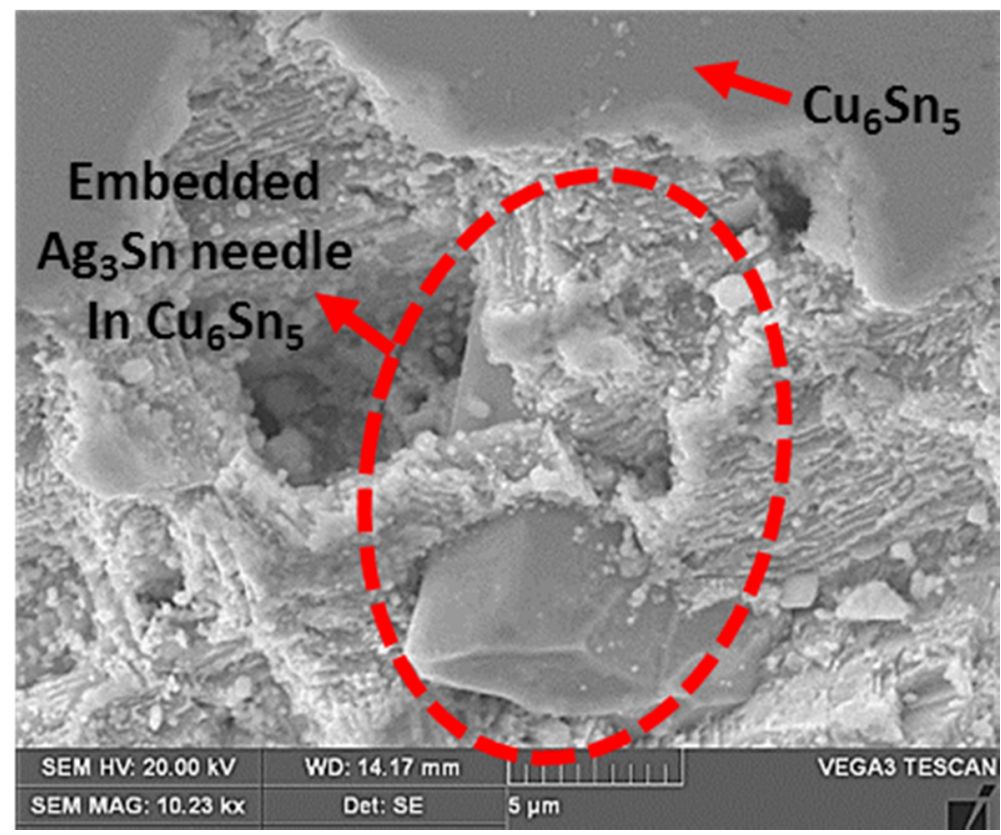

Fig. 6 : Representative SEM image of a needle like $\mathrm{Ag}_{3} \mathrm{Sn}$ IMC embedded in $\mathrm{Cu}_{6} \mathrm{Sn}_{5}$ layer at soldering temperature of $260^{\circ} \mathrm{C}$ and soldering time at 30 minutes. 


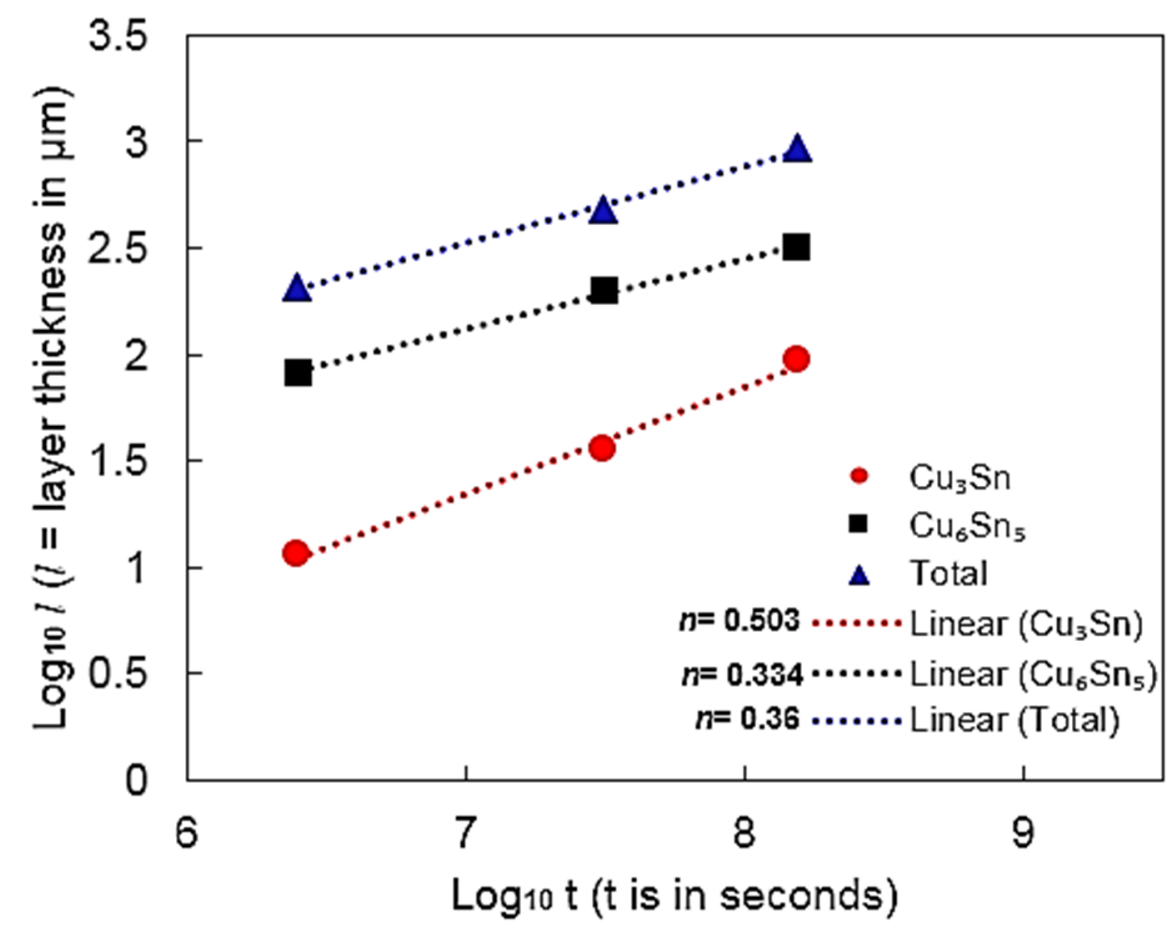

Fig. 7: Log-Log plot of IMC layer thickness in one interfacial side vs. soldering time.
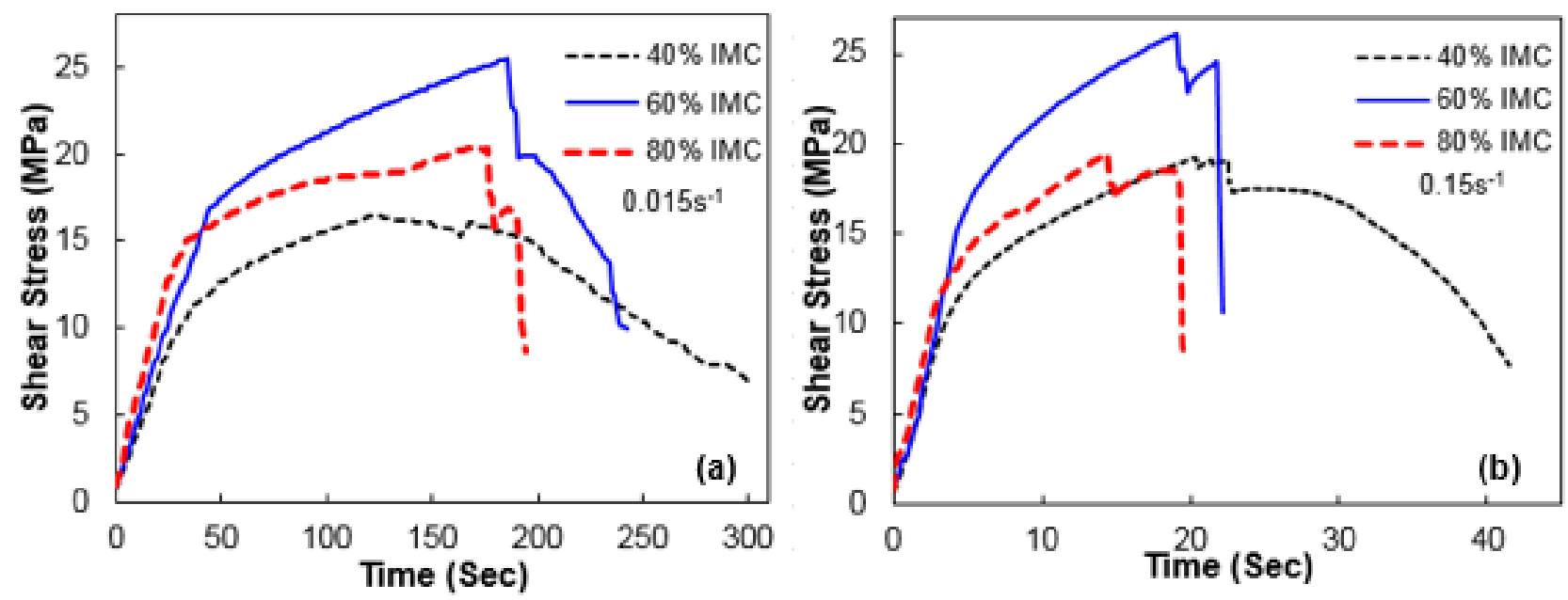

Fig. 8 : Shear Stress Vs. Time plot for solder joint samples at (a) $0.015 \mathrm{~s}^{-1}$, and (b) $0.15 \mathrm{~s}^{-1}$ shear strain rates. 

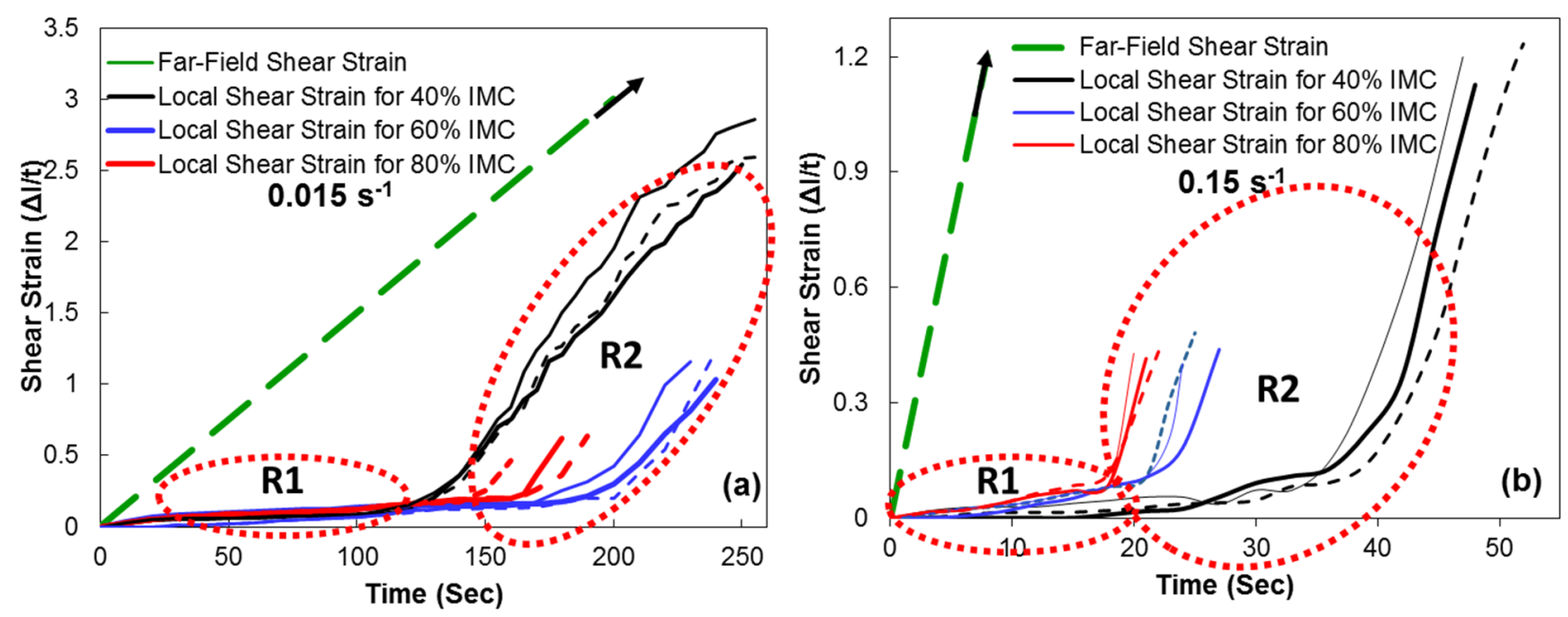

Fig. 9: Changes in far-field and local shear strains with respect to time at (a) $0.015 \mathrm{~s}^{-1}$, and (b) $0.15 \mathrm{~s}^{-1}$. The local shear strains were calculated using the technique described in section 2.3. Farfield shear strain is calculated from the cross-head displacement divided by the joint thickness.
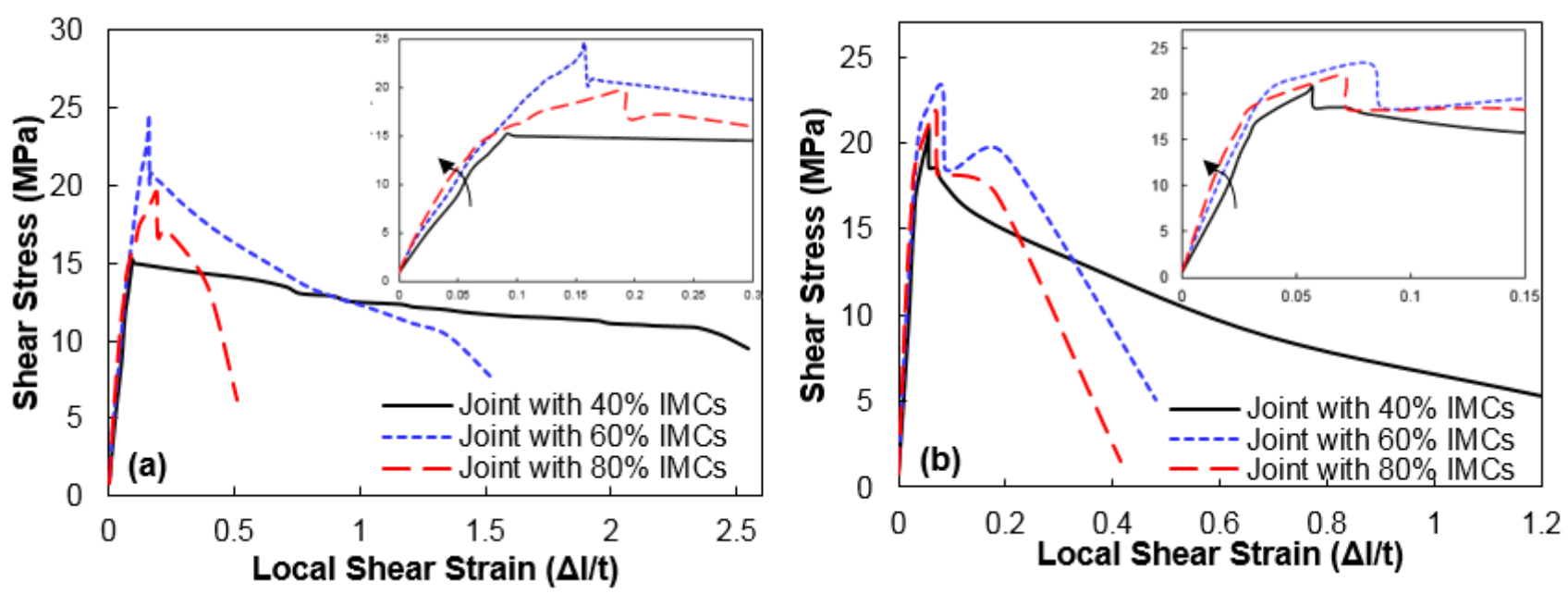

Fig. 10: Shear stress- shear strain curve for test specimens tested at (a) $0.015 \mathrm{~s}^{-1}$, and (b) $0.15 \mathrm{~s}^{-1}$ shear strain rate. The figures have magnified view of elastic region in the inset 

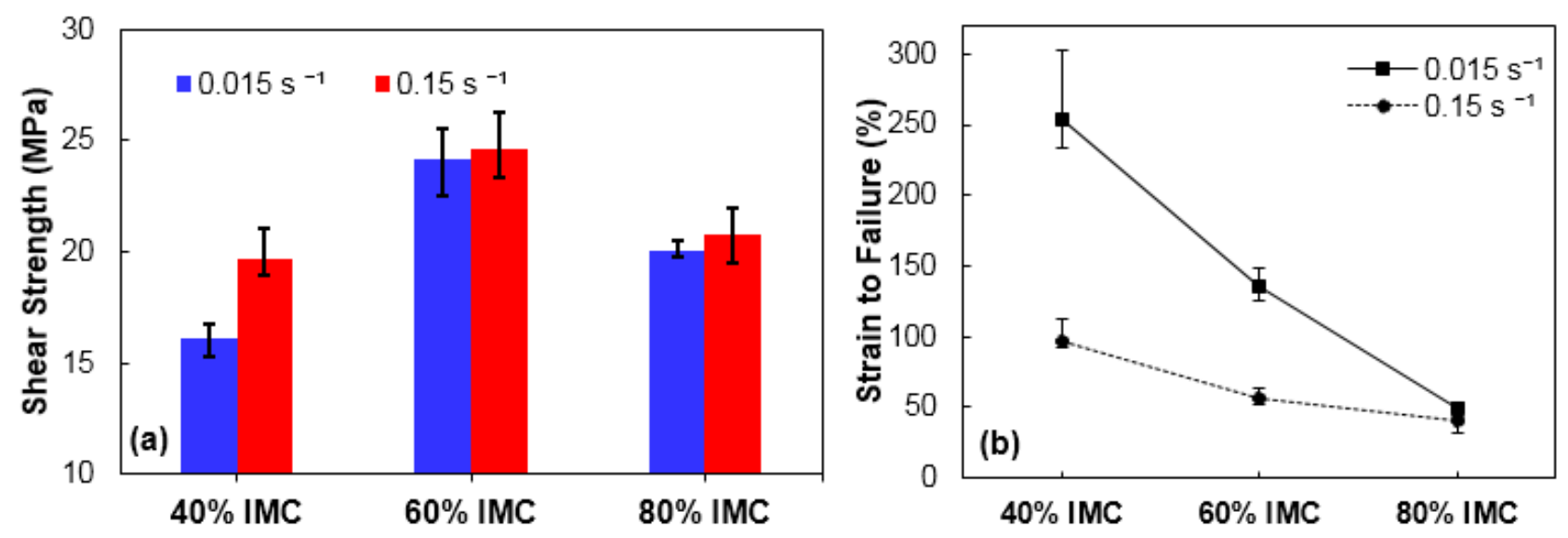

Fig. 11 : (a) Shear strength(MPa) and (b) shear strain (\%) to failure with respect to volume fraction of IMCs at a shear strain rate of $\mathbf{0 . 0 1 5} \mathrm{s}^{-1}$ and $\mathbf{0 . 1 5} \mathrm{s}^{-1}$
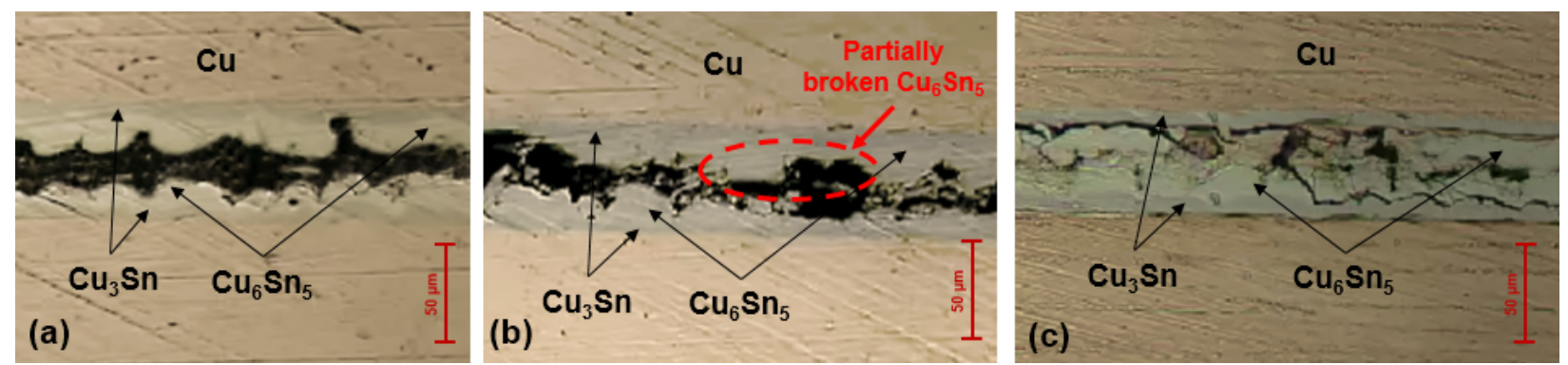

Fig. 12 : Representative optical microscopic image taken during the in situ lap-shear test of joint sample with (a) 40\% IMC with intact $\mathrm{Cu}_{6} \mathrm{Sn}_{5}$, (b) 60\% IMC with partially broken $\mathrm{Cu}_{6} \mathrm{Sn}_{5} \mathrm{IMC}_{\text {, }}$ and (c) $80 \%$ IMC with $\mathrm{Cu} 3 \mathrm{Sn} / \mathrm{Cu}_{6} \mathrm{Sn}_{5}$ delamination. Image quality is average due to the limitation in microscope resolution. 

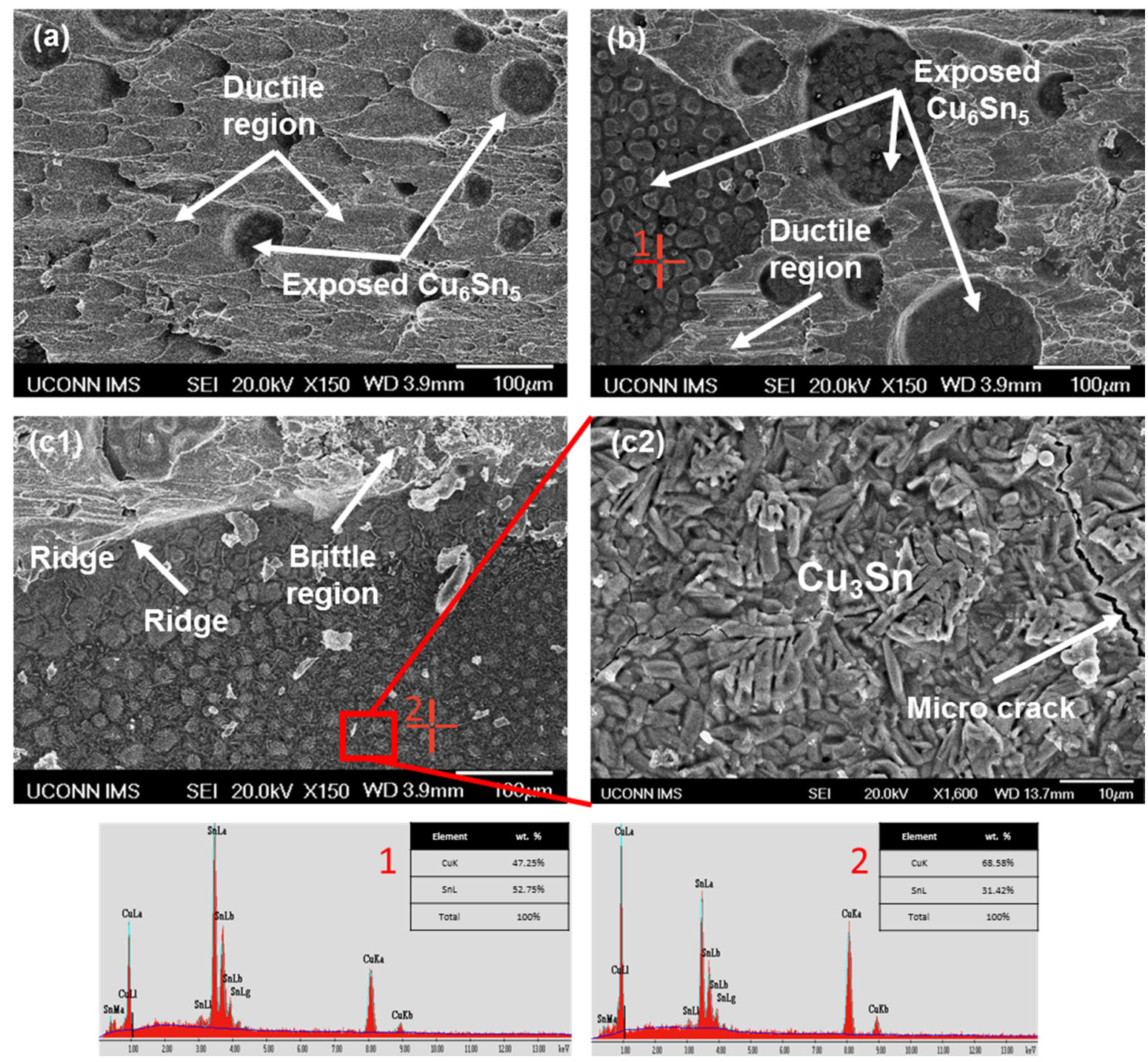

Fig. 13 : Representative SEM fractograph images of solder joints with (a) 40\% IMCs, (b) $60 \%$ IMCs, (c1) $80 \%$ IMCs, and (c2) magnified view of exposed $\mathrm{Cu}_{3} \mathrm{Sn}$ at $80 \%$ IMCs samples. These images were taken from samples tested at $0.015 \mathrm{~s}^{-1}$ shear strain rate. EDX analysis indicating possible (1) $\mathrm{Cu}_{6} \mathrm{Sn}_{5}$, and (2) $\mathrm{Cu}_{3} \mathrm{Sn}$ IMC. 

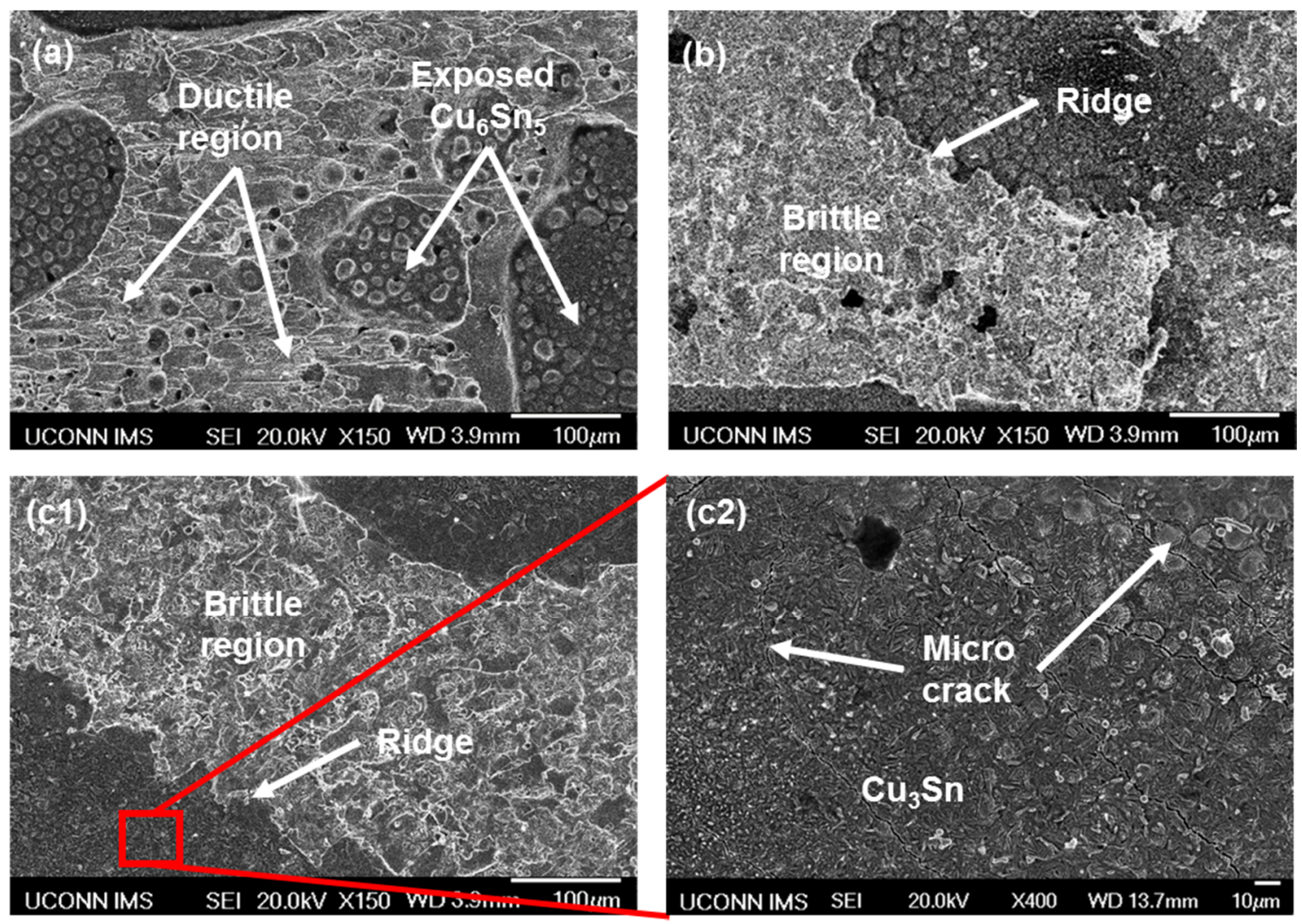

Fig. 14 : Representative SEM fractograph images of solder joints with (a) 40\% IMCs, (b) 60\% IMCs, (c1) 80\% IMCs, and (c2) magnified view of exposed $\mathrm{Cu}_{3} \mathrm{Sn}$ at $80 \%$ IMCs samples. These images were taken from samples tested at $0.15 \mathrm{~s}-1$ shear strain rate

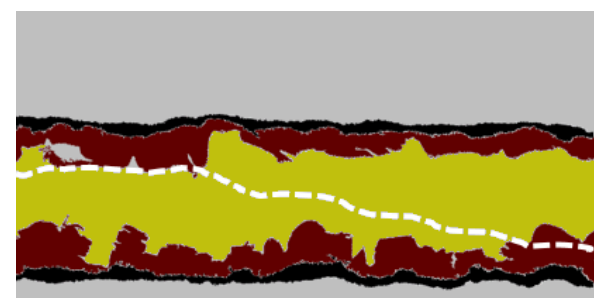

(a)

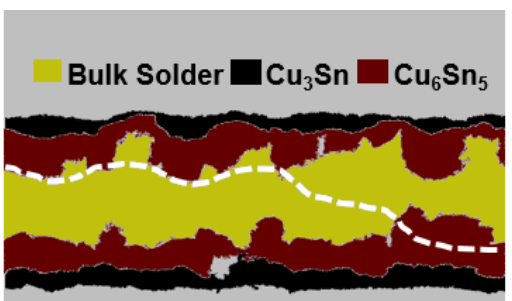

(b)

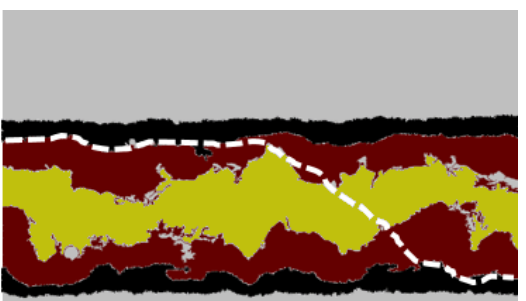

(c)

Fig. 15: Proposed crack propagation and fracture path for solder joints with (a) 40\% IMCs, (b) $60 \%$ IMCs, and (c) $80 \%$ IMCs. These images are not to scale 